observer draws away the movable part, which readily rolls on a railway. The extremity of the teles zope bearing the mirror of the objective is thus left uncovered, while the astronomer, ensconced in his fixed part as in his own room, and sheltered from all inclemencies of weather, stidies the infinitely great in conditions as comfortable as those of the naturalist w'xo examine; under his microscope the infinitely little.

Seeing it is but just that those who bear the burden should also enjoy the honour, we again state that the optical part of this instrument has been executed by the Brothers Henry, and the mechanical part by MM. Eichens and Gauthier.

\section{THE INSTITUTION OF MECHANICAL ENGINEERS}

THE Institution of Mechanical Engineers have held their autumn meeting this year in Birmingham -a town which for many years was the headquarters of the Society. The returning to their former seat was specially opportune, because the first paper on the list related to one of the greatest of Birmingham worthie;, viz. James Watt. The title of the paper was "On the Inventions of James Watt, and his Models preserved at South Kensingand Handsworth." The author is Mr. Ed war $1 \mathrm{~A}$. Cowper, who, frum his long connection with en rineering both personally and through his futher and uncle, is perhaps as well fitte $d$ as any $m$ in in England to trace out the course of Watt's inventions. This he $\mathrm{h}$ is endeavoured to do, using as his main guide the numerous model s preserved partly at the South Kensington Museum, partly at the Patent Office Museum, and partly at James Watt's house at Hands sorth in Birmingham. Some of the models at South Kensinjton were in danger of falling altogether to pieces from dry rot an 1 decay, but o wing to the exertions o? Mr. Sandham, the curator of this department, they have, as far as possible, been rep iired; whilst, in addition, a complete set of photographs has been taken, whi h. even if the molels themselve; should cease to exist, would preserve their appearance and construction to future ages.

The sequance of James Watt's inventions with regard to the steam engine is stated at the end of Mr. Cowper's pıper as follows :-

Firstly, in 1769 he made an invention (the separate contenser) which was praztically an improvement on the Newcomen enrine, the effect of which was to work pum ping engines more economically and quickly.

Secondly, in $178 \mathrm{r}$ he produced rotative power for driving factories, obtaining it in a manner by having a heavy bulance weight to act one way whilst the steam acted the other way; however, the obtaining rotative motion by steam was an enorm ous advantage, far greater in its effect, in the author's opinion, than the improvement in the pu nping engine.

Thirdly, the crowning invention of 1782 made the steam engine the one uieful motive power, by making it double-actins and fit to drive cotton mills, flour mills, and all other machinery requiring rezular rotative motion.

These various stages are illustrated by the models above mentioned. It is indeed doubtful whether there exists at present any model embodying the first idea of the separate condenser; but there is a most interesting model at South Kensington showing the condensation of steam in a separate surface condenser, composed of a large number of vertical tube; and provided with an air pump. This form of contenser, which in many cases, such as marine engines, has superseded all others, is thus proved to have been invented by James Watt, and not only invented, but brought to a high degree of perfection. The arrangements in this molel, according to Mr. Cowper (than whom there can be no better authority), are in points equal to the best modern examples of surface condensation.

The only model actu ally exhibited was an engine of the character of Watt's patent of I77I. It is single acting, and has an open-topped cylinder, air pump, and condenser. There is a heavy bob on the connecting rod, which is used to help the piston up, while the vacuum formed below it causes it to descend on the return stroke, thus obtaining rotative motion. This engine, however, has a crank, and it is known that for many years Watt was afraid to use the crank in his engines, as it was supposed to be barred by another patent : it is true that his patent of I77 I shows a crank composed of a pin in a disk, but this is carefully termed "the poin" of attach. ment of the connecting rod." In practice, however, he used other methods, chiefly the well known sun and planet motion. Of this there are several different forms, which are illustrated by models at South Kensington. There is also a device consisting of a long rack or la 1der fixed to the end of the connecting rod and digging into the teeth of a spur wheel on the engine shaft; the rol being guided by means of rollers running in a guide plate, so as to keep it in gear throughout the revolution.

Turning now to the I 782 patent, we find what Watt describes as "the new improved en rine, the piston of which is pressed forcibly both up wards and downward; by the power of steam," that is to say, the en rine is no longer single-acting, but double-acting. Here the chain hitherto used between the piston-rod and beam is replaced by a parallel motion, and the engine takes very much the form which was still common for shop engines within recent years. A good model of sush an engine exists in the South Kensington Museum.

Some variations of this engine, probably made subjequeiatly, are also illustrated by models, such as the Bull engine, in whi sh the piston-rod passe.s out through the bottom of the cylinder, and takes holl of a beam placed lower down.

Still more interesting are Watt's prop ssals to ma'ze use of the expansion of stea $n$ for the saving of fuel; a diagram in one of his specifications shows that he fully understoot this action, and he gives several methols by which the load upon the piston may be varied so that when the pressure is least it shall have least wor'k to do. One of these is to mount a weight high up above the beam, which would be lifted when starting from either end of the stroke, and fall after passing the centre; this has been used even in recent times with good re sulcs. Several $\mathrm{m}$ : scellaneous inventions of high interes! are also described; one of these is the well-known invention of the steam indicator in probably its earliest and rudest form. Another is a counter for telling the revolutions of an engine, of which an actual specimen in good preservation remains in the Patent Office Museum.

There is also an arangement for obtaining rotary $\mathrm{m}$ )tion in opp ssite directions out of the same engine by means of two connecting rods starting from a cross-head at one end of the beam, but working opposite ways. Another model shows two hammers worked by a single engine, the one lifted from the belly like an ordinary forge hammer, and the othar by depressing the till like a tilt hammer. A yet more curious device is a semi-rotary engine, of which an unfinished model remains in the Watt Room at Heathfield Hall. Here there is a pi iton fixed in a radial line to the shaft, within a large disk or cylinder. Inside this cylinder, at one part, is a fixed support, against which the steam presses each way as it acts against the pist in, in either one direction or the other. The reciprocating shaft was made to act by a spur wheel on two racks attached to the pump rods. Watt also invented a very simple form of rotary engine, which, as Mr. Cowper states, has probably been reinvented at least fifty tim 2 s since 1782 , the year of his patent. 
This leads us to notice the Watt Rcom, or attic workshop of James Watt, which still remains at Heathfield Hall precisely as he left it-his lathe and bench standing at the window, his tools lying about, and his old leather apron hung on the vice. There are numerous shelves with drugs and parcels on them, chiefly relating to his invention of copying-ink, and nests of small drawers full of tools; but the principal objects which strike the attention are two large machines for copying sculpture, whether in marble, alabaster, or wood. One cf them copies to the exact size of the original, but the other is a reducing machine, taking a copy on a very reduced scale. The construction of both machines is described in the paper, and bears testimony to the inventive and mechanical genius of James Watt. The principle in each case consists in using a bar or slide, having at one end a blunt point to feel over the surface of the model, and at the other end a quick-running drill to cut away the surface of the material operated on. This drill is worked by a light cord attached to an ordinary foot lathe, whilst the bar, by means of a skilful arrangement of trussed frames, is made movable in any direction as the feeler passes over the model. The mocel and work can also be rotated, so as to be set at an angle for handcutting, \&c. The drills and cutters, of which a large number are preserved, are excellent in their design and workmanship. These machines were apparently the amusement of Watt's iate years, and are frequently referred to in his correspondence. They were never protected in any way, and partly perhaps for that reason have never been followed up and brought to perfection.

The second paper read was a report by the Research Committee on Friction. The Institution experiments on friction, which have been long delayed, have at length been carried so far as to admit of the fublication of an interim report, prepared by $\mathrm{Mr}$. Beauchamp Tower, which proves to be of great interest. They are, properly speaking, experiments on lubrication, being conducted on a 6-inch steel shaft or journal, which could be run at any given velocity, and on which rested a brass bearirg carrying a loaded frame. By altering the load on this frame the pressure per square inch on the brass could be altered; and the temperature could also be altered by means of gas jets under the journal. As a standard of comparison experiments were first tried with the underside of the journal running in a bath of oil, so as to give the maximum of lubrication. The results of these experiments were to show that the friction of bearings under such circumstances follows the laws of liquid rather than (as usually assumed) of solid friction. These laws are very different. Solid friction varies directly as the pressure per unit of area, is independent of velocity at low speeds (Morin), but decreases with increasing velocity at high speeds (Galton, \&c.). Liquid friction, on the other band, is independent of the pressure per unit of surface, is directly dependent on the extent of surface, and increases as the square of the velocity. In fact it is not friction at all, but the shearing of one part of a more or less viscous fluid across another, as the above law plainly indicate. Now the Institution experiments show that, in the case of oil-bath lubrication, there is really a film of liquid oil surrounding the journal and keeping it away from the brass; and that what is called journal friction is really the shearing of one part of this film (ver the other. In such cases the friction may be exceedingly small : in some of these exreriments it actually was as low as $1 /$ Iocoth, and $1 / 500 t h$ is easily attained. This is much below what is generally supposed to obtain. The limit of pressure appeared to be about $600 \mathrm{lbs}$. per square inch. Beyond this the oil is squeezed out, and the metal "seizes." This is of course with high speed and constant pressure; with low sfeeds and intermittent pressure (as was pointed out in the discussion) very much higker pressures are admissible.
So far the experiments were satisfactory; but when the oil-bath was replaced by ordinary modes of lubrication, great difficulties were experienced. When the oil was introduced from above through grooves in the brass, it was found that, however these were cut, and at whatever part of the brass then opened, the Learing seized at a comparatively low pressure. The fact that such methods do as a matter of fact answer with ordinary railway vehicles is accounted for, it is supposed, by the end play of such bearings, and probably also by the general vibration. When, however, a pad fed with oil by capillary attraction from a bath below, was placed below the journal, so as to press lightly against it, satisfactory results were obtained, although the lubrication was so slight as only to appear to the touch as a slight greasiness. The laws here, however, approximated to those of solid friction, and probably the oil merely acts to fill up the little inequalities of the metal, and so practically render it smoother.

A curious subsidiary result should be noticed. When the oil-bath experiments were in progress, acivantage was taken of the brass being removed to drill a hole in it for the subsequent tests with ordinary lubrication. On resuming the running, however, the oil was found in the hole, and on a pressure-gauge being attached, the finger rose to above 200 lbs. per square inch, which was the limit of its indications. This pressure was above the average pressure on the brass, and shows clearly that the surfaces are separated by a continuous film of oil, having at $\epsilon$ ach point an actual hydrostatic pressure due to the external pressure which obtains at that point.

$\mathrm{Cn}$ the whole, these experiments, while to a great extent confirming the well-known researches of Prof. Thurston in America, tbrow a good deal more light on the curious phenomena and laws of journal friction. Their results (including some on temperature, which was found to have a marked influence in diminishing friction) are contained in a series of tables, which our sface forbids us to pubish, but which can no doubt be obtained, by any one interested, from the offices of the Institution, at 16 , Victoria Chambers, Westminster.

\section{NORDENSKJÖLD'S GREENLAND EXPEDITION ${ }^{1}$}

\section{II.}

I $N$ my report of the exfedition of 1870 I drew attention 1 to a clayey mud which is found in circular cavities, from one to three feet in depth, on the surface of the inlard ice, nct only near the shore, but even as far inland as we reacked on that occasion. My companion on that occa. sion, Prof. Berggren, discovered that this substarce formed the substratum of a feculiar ${ }^{2}$ ice-flora, consisting of a quantity of different microscorical plants (algæ), of which some are even distributed beyond the clay on the ice itself, and which, in spite of their insignificance, play beyond doubt a very important part in nature's economy, from the fact that their dark colour far more readily absorbs the sun's heat than the bluish-white ice, and thereby they contribute to the destruction of the icesheet, and prevent its extension. Undoubtedly we have, in no small degree, to thank these organisms for the melting away of the layer of ice which once covered the Scandinavian peninsula. I examined the appearance of this substance in its relation to geology, and demonstrated :-

I. That it cannot have been washed down from the mountain ridges at the sides of the glaciers, as it was found $\epsilon$ venly distributed at a far higher elevation than

\footnotetext{
1 Ccntinued from p. 13

2 Lately described by Prcf. V. Wittrock. "Om Snöns och Isens Fiora, Särskildt i Arktiska Trakterna." Ur "A. E. Nordenskjöld, Studier och Forskningar föranl $\epsilon d d a$ af mina resor $i$ höga Norden." (Stockholm, $r 88_{3}$.) See NATURE, vcl. xxviii. p. 304 .
} 